\title{
Experimental and Numerical Investigation of Annular Casing Impingement Arrays for Faster Casing Response
}

\author{
Andrew Dann,; Priyanka Dhopade, Marko Bacic, \\ and Peter Ireland \\ Osney Thermo-Fluids Laboratory \\ Department of Engineering Science \\ University of Oxford \\ Oxford, Oxfordshire OX2 0ES \\ United Kingdom \\ Email: andrew.dann@eng.ox.ac.uk \\ Leo Lewis \\ Thermals Specialist - Structural Systems Design \\ Rolls-Royce plc \\ Derby, DE24 8BJ \\ United Kingdom \\ Email: leo.lewis@Rolls-Royce.com
}

\begin{abstract}
The Transient Heat Transfer Facility was developed to test fullscale high pressure compressor and turbine casing air systems using gas turbine engine representative secondary air system conditions. Transient casing response together with blade and disc responses governs achievable tip clearances in both compressors and turbines. This paper investigates the use of air impingement as a means to speed up the casing response. The thermal growth of the casing was characterised by surface temperature rise over a given period to assess achievable dynamic response. The experimental set-up resembles a typical aircraft engine with features that can lead to circumferential temperature non-uniformities, as evident from the experimental results. The experimental data was compared against numerical predictions from a conjugate heat transfer model. The studies show the significance of analysing the full annulus, at engine representative conditions and the benefit of an impingement array to potentially speed up casing response for future engines.
\end{abstract}

\section{Nomenclature}

C axial length of casing

Fo Fourier number

$\mathrm{L}$ length of impingement jet hole, $\mathrm{mm}$

L1 leakage 1

L2 leakage 2

${ }^{*}$ Address all correspondence to this author. leakage 3

pressure, $\mathrm{Pa}$

quadrant

Reynolds number

temperature, ${ }^{\circ} \mathrm{C}$ or $\mathrm{K}$

air temperature in outer cavity, ${ }^{\circ} \mathrm{C}$ or $\mathrm{K}$

specific heat capacity, $\mathrm{J} /(\mathrm{kg} . \mathrm{K})$

diameter of impingement jet hole, $\mathrm{mm}$

heat transfer coefficient

thermal conductivity, $\mathrm{W} /(\mathrm{m} . \mathrm{K})$

casing thickness, $\mathrm{m}$

mass flow rate, $\mathrm{kg} / \mathrm{s}$

time, $\mathrm{s}$

streamwise flow direction, $\mathrm{mm}$

spanwise flow direction, $\mathrm{mm}$

jet stand-off distance, $\mathrm{mm}$

thermal diffusivity, $\mathrm{m}^{2} / \mathrm{s}$

eigenvalues

non-dimensional temperature

fluid density, $\mathrm{kg} / \mathrm{m}^{3}$

circumferential position,

eigenfunction time dependent coefficients

eigenfunction

Subscript

$f \quad$ fluid

fluid fluid 


$\begin{array}{ll}i & \text { casing inner wall } \\ o & \text { casing outer wall } \\ m & \text { eigenfunction subscript } \\ 0 & \text { beginning of transient test period } \\ \text { outer } & \text { wall outer surface } \\ \text { metal } & \text { metal property } \\ \text { tot } & \text { total } \\ \text { Superscript }\end{array}$

$0 \quad$ beginning of transient test period

\section{Introduction}

Tip clearance is defined as the radial distance between the end of a blade and the abradable tip seal [1]. The leakage flow through this region contributes to the overall loss experienced by the compressor by introducing irreversible mixing and diffusion, while the turbine tip leakage flow lessens the amount of work that can be extracted from the turbine. This can have an adverse effect on the performance and stability of the engine [2].

Tip clearance is not constant during a given flight cycle, both in the compressor and turbine, illustrated in Fig. 1(a). These variations in tip clearance with engine operating points are caused by the displacements and distortions experienced by the stationary and rotating components due to varying loads on the components. These loads can be categorised into engine loads and flight loads. Flight loads include inertial, aerodynamic and gyroscopic loads, whereas engine loads consist of centrifugal, thermal, internal engine pressure and thrust loads [1]. Flight loads produce asymmetric tip clearance changes, while engine loads can result in both asymmetric and axisymmetric tip clearance changes.

In the example of a high pressure turbine, particularly at take-off, the rotor experiences a rapid increase in centrifugal and thermal loads, causing the rotating components to rapidly grow radially outward [1]. The casing expands at a slower rate only due to heating. This results in a minimum tip gap, known as a "pinch point", illustrated in Fig. 1(a). As the casing continues to heat up and expand, the tip clearance increases beyond the pinch point.

Achievement of good cruise tip clearances involves matching cruise closure as closely as possible to the pinch point closure, to avoid having large tip clearances which result in reduced engine efficiency. However this again is fundamentally limited by the casing/disc time constants mismatch.

Traditionally, the relationship in a compressor/turbine stage has been that the casing time constant is faster than that of its corresponding rotor disc, shown in Fig. 1(b), due to the casing having a smaller volume than the rotor disc. However, disc designs have since become lighter and some modern engine stages now have "inverted" transient pinch points, shown in Fig. 1(c). The challenge with inverted pinch points is to speed up the casing response through an enhanced air system generated heat transfer coefficient (HTC), in order to match the casing and rotor transient thermal response, shown in Fig. 1(d). Consequently there is motivation to match the

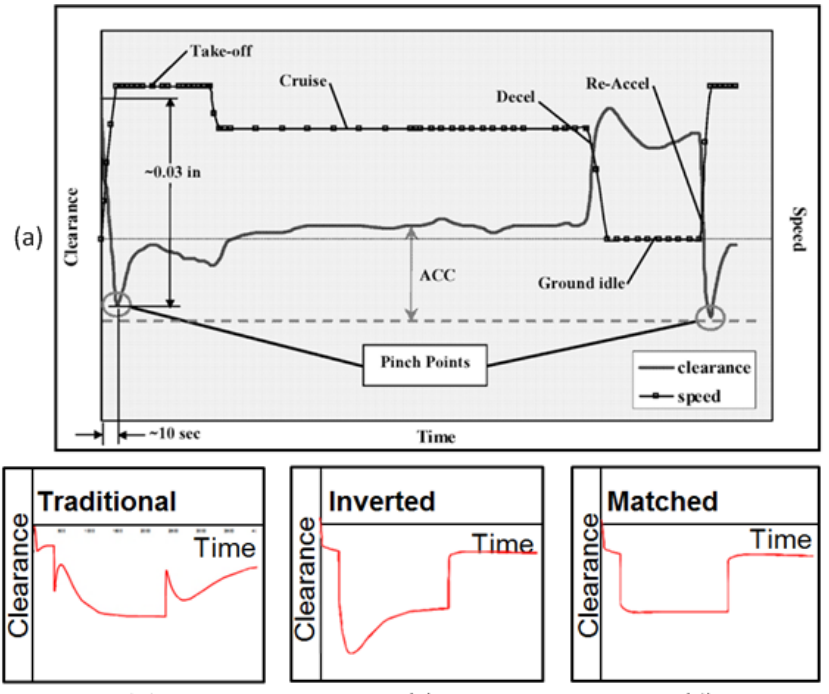

(b)

(c)

(d)

Fig. 1: Traditional flight cycle closure traces with fast casing and slow rotor time constants, compared to inverted and matched relationships [1]

time constants of the disc/rotor and the impingement system presented in the current study is one possible solution.

A secondary air system that uses impingement heat transfer is an effective method of enhancing the HTC and is widely used in aero-engine cooling applications [3]. In the present study, impingement is used as a means of heating the casing to enable future engine designs to better match the thermal response of the rotor disc and casing.

Large gas turbines used for power generation also experience high temperature flows through the tip region in the high pressure turbine, leading to thermal loads on the blade tips that could result in blade tip burnout and oxidation [4]. Many studies in this area have focused on analysing the heat transfer on the surface of the blade tip and in the near tip region [4-7], in order to advance blade tip geometries to cope with the thermal loads. However, an improved match between the transient responses of the casing and disk would also benefit industrial gas turbines by providing more control over the tip clearance.

The majority of studies related to tip clearance control for aero-engines use scaled down facilities with cold flow, coupled with CFD $[8,9]$ to investigate case cooling. However, the casing transient response that influences tip clearance is also heavily dependent on the heat transferred to the casing inner surface. This inner heat transfer is a function of the secondary flow aerodynamics which tends to be low speed. Furthermore the flow is not well defined due to the complicated segment structure and multiple seals causing a number of unpredictable leakage paths. To the best of the authors' knowledge, it is difficult to find evidence of the facilities that have investigated low-speed secondary air system flow around the full-scale annulus of a representative turbine casing at engine temperatures with realistic leakage paths.

The challenge with generating a circumferentially uniform enhanced HTC is the inclusion of real engine effects 
due to fixtures, sealing systems, cavities formed by various internal components, large surface areas and manufacturing tolerances. These real engine effects can result in leakage paths, varying thermal inertias and circumferentially non-uniform HTCs which can have a significant impact on the effectiveness of the secondary air system and therefore the achievement of good tip clearance. The novelty of the present study is the inclusion of these effects and understanding their impact on the HTC enhancement delivered to the casing. This would allow for a robust setting of the inner casing heat transfer and therefore the casing time constant during transients in order to improve the casing/rotor response matching and subsequently the running cruise tip clearance.

In order to design an experiment that was representative of an engine HP compressor/turbine, it was necessary to use:

- the full-scale casing diameter,

- a three-dimensional test section,

- a realistic sealing system,

- representative casing geometry that includes flanges, fixtures, etc.

- high temperatures and pressures corresponding to those in a real HP compressor or HP/IP turbine section.

The last point involves matching the higher-stage HP compressor bleed air properties used by the HP and IP turbine secondary air systems. This is challenging due to the prohibitively high costs associated with:

- generating air with these properties, which may require the use of a small gas turbine $[10,11]$

- the use of high temperature materials due to thermomechanical constraints [12].

The work in this study is aimed at understanding the flows in secondary air systems and the ability to enhance heat transfer within this region. This enhancement can then be used by engine designers to control the thermal expansion of the casing, and therefore lead to improved tip clearance control and improved engine performance. In addition, improved tip clearance control in the high pressure turbine can also alleviate tip seal degradation due to blade rubs [1].

The Transient Heat Transfer Facility (THTF) was developed and commissioned at the University of Oxford to simulate the transient response of an engine representative casing by measuring the air and metal temperatures during a given test period. It was designed to reproduce 3-D flow conditions and interactions in the seal segment cavities of casings such as the one shown in Fig. 2. The present study aims to use the THTF to analyse the transient response of the casing due to an enhanced HTC from an annular impingement array.

A numerical model of the experiment was also developed using a conjugate heat transfer $(\mathrm{CHT})$ method in order to:

- compare the transient response of the metal casing to experimental data,

- assess the applicability of the CHT as a tool to design annular casing impingement arrays,

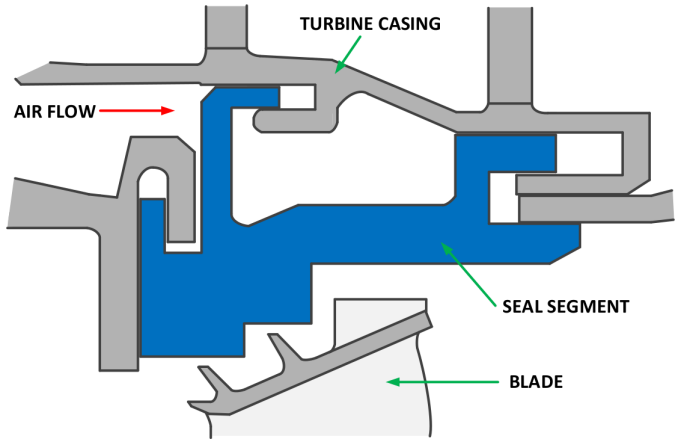

Fig. 2: Schematic of a typical shrouded turbine segment cavity (adapted from [13])

- help estimate some of the uncertainties involved with instrumentation of the facility using the detailed, spatially resolved temperature maps.

This paper experimentally and numerically investigates the following:

1. Temporal casing response: the impingement array designs are compared in terms of average temperature rise and HTC delivered to the casing, calculated using the analytically derived explicit solution for heat conduction in a finite wall.

2. Uniformity of case heating: the variation in the uniformity of case heating for each of the impingement designs may be different,

3. Total flow consumption of the system: there may be variation when comparing impingement plate cases with regards to leakage between and around the plates.

\section{Description of Test Facility}

The THTF has been recently commissioned at The University of Oxford. A more detailed description of the rig is given in Van Paridon et al [10]. A brief description is given here to clarify the facility capabilities and operation.

The rig consists of five main systems which support the experimental apparatus. These are:

1. Air supply and pressure relief.

2. Heater.

3. Pressure vessel and supporting high temperature pipework and valves.

4. Vent.

5. Data acquisition and Programmable Logic Controller (PLC).

The facility pressure vessel and rear valve arrangement can be seen in the photo in Fig. 3. Air is supplied to the rig from the laboratory main supply tanks at $2.76 \mathrm{MPa}$. It is regulated to the working pressure (1.5 MPa or less) and then protected by a three tier pressure relief system. The air passes through a high powered $(650 \mathrm{~kW})$ resistance type heater which can supply up to $1 \mathrm{~kg} / \mathrm{s}$ of pressurised air in the working section at up to $650 \mathrm{~K}$. The heated air is fed into the pressure vessel and through the experimental apparatus 


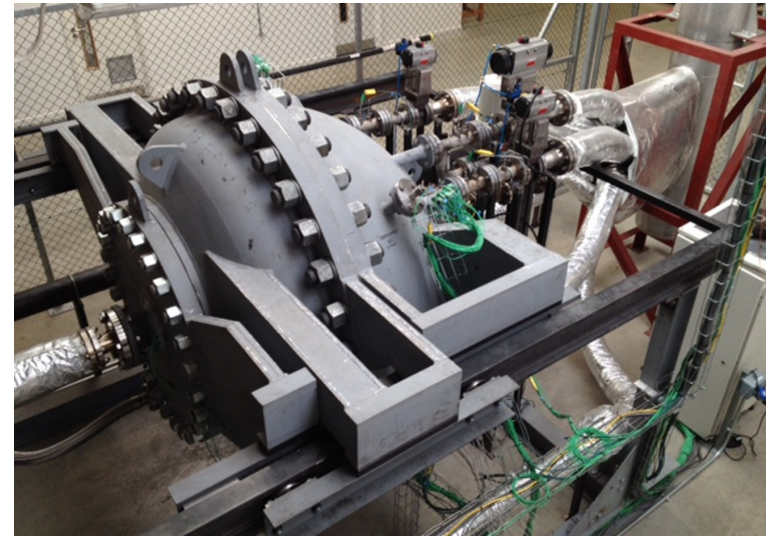

Fig. 3: Photo showing the pressure vessel and rear valve arrangement

and then vented to atmosphere through the detuner/vent system. The rig is controlled and data is recorded by a PLC and computer located in a control room (not shown).

The experimental apparatus is illustrated in Fig. 4. Heated air enters at the main inlet and is directed around a centre-body which creates an annulus. A generic casing constructed from BS1501-316 stainless steel [14] is mounted in the working section and creates the outer surface of the annulus. The impingement plates are mounted on the casing inner surface and when the off-take valves are opened, the hot air impinges on the casing causing it to expand. The casing is instrumented with 48 static pressure taps and 88 thermocouples which allow evaluation of the impingement process. An outer cavity is created between the working section and the main vessel outer wall and this area is cooled by air at ambient temperature. The air continuing through the annulus is controlled by a variable globe valve and is vented to atmosphere through the detuner/vent. The air passing through the impingement plates is controlled by fast-acting butterfly valves and is also vented to atmosphere through the detuner/vent. A bypass allows the correct mass of hot air to be excluded from the experiment until conditions are ready for the test to begin. At this point the bypass is shut and the off-takes opened.

\section{Impingement System Design}

For the current tests, the THTF test section was configured with a full-scale high pressure turbine casing analogue. This casing accepts 20 impingement plates mounted on the internal surface of the casing making up a full circumference with an approximate radius of $0.4 \mathrm{~m}$. Each plate is an arc of just less than $18^{\circ}$ (to allow a small space between plates) and is approximately $115 \mathrm{~mm}$ long in the axial direction. Eight impingement plate configurations with varying numbers of holes and spanwise and streamwise hole spacing were proposed as outlined in Tab. 1. The hole configurations were based on previous studies investigating the most effective thermal response $[15,16]$ and ranged from 5 to 13 hole diameters for streamwise spacing (x/d) and 6 to 9 hole diameters

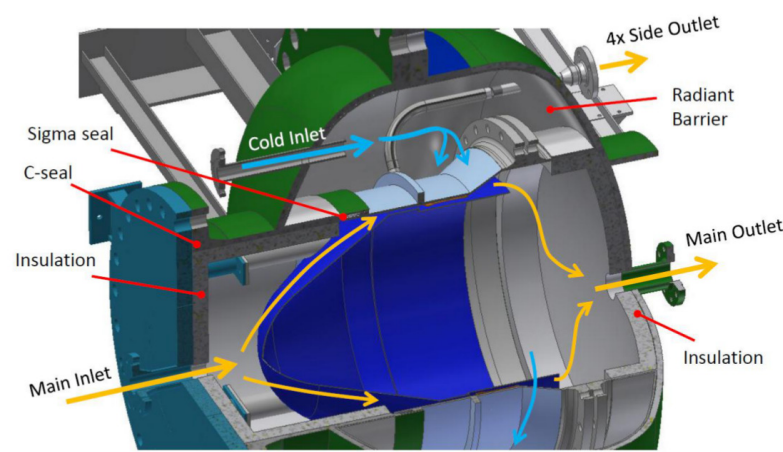

Fig. 4: Detail of the pressure vessel inner working section

for spanwise spacing $(\mathrm{y} / \mathrm{d})$. The $\mathrm{z} / \mathrm{d}$ (where $\mathrm{z}$ is the stand-off distance) for all plates was 4 where the hole diameter $d$ was constant at $1 \mathrm{~mm}$. All plates attempted to concentrate the rows around the thermocouple positions in the second axial half of the plate.

Table 1: Impingement plate designs considered. Case (a) has approximately the same spacing in $\mathrm{x}$ and $\mathrm{y}$ directions. Case (b) has larger $\mathrm{x}$ spacing and smaller y spacing.

\begin{tabular}{lllll}
\hline Design & \multicolumn{4}{c}{ Number of Holes } \\
\hline & $\begin{array}{l}\text { Case 1 } \\
\text { Case 2 }\end{array}$ & Case 3 & Case 4 \\
& 640 & 800 & 960 & 1200 \\
\hline Case (a) & & & & \\
x/d & 7.6 & 9.6 & 7.7 & 6.2 \\
$\mathrm{y} / \mathrm{d}$ & 8.0 & 9.0 & 8.0 & 6.0 \\
\hline Case (b) & & & & \\
$\mathrm{x} / \mathrm{d}$ & 12.3 & 12.4 & 10.2 & 8.2 \\
$\mathrm{y} / \mathrm{d}$ & 8.0 & 8.0 & 8.0 & 6.0 \\
\hline
\end{tabular}

The eight generic plates were investigated using steady RANS CFD (see Sect. 6.1). The best performance, based on the highest area-averaged HTC under conditions of constant impingement mass flow rate, was recorded for Plates $1 \mathrm{~b}$ and $2 b$. Ten plates of each of these two configurations were manufactured in maraging steel [17] by laser sintering. These were then installed in the test section of the THTF according to the set-up shown in Fig. 5 with five plates (each plate denoted by the small divisions in each of the quadrants) of each design opposing each other in a rainbow set. The rain- 


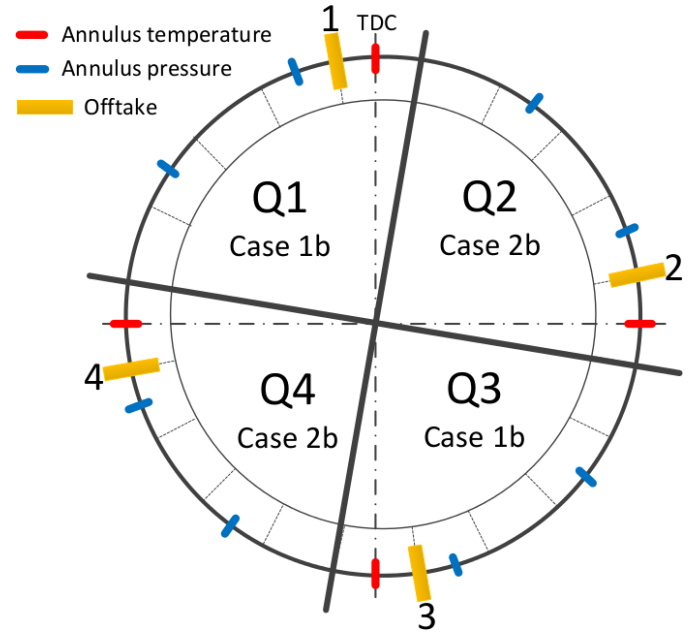

Fig. 5: Rig reference
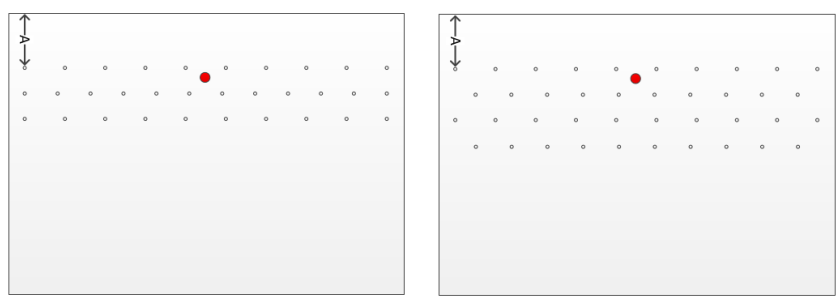

Fig. 6: Thermocouple position on the two impingement plate configurations. The distance ' $A$ ' is $17 \mathrm{~mm}$.

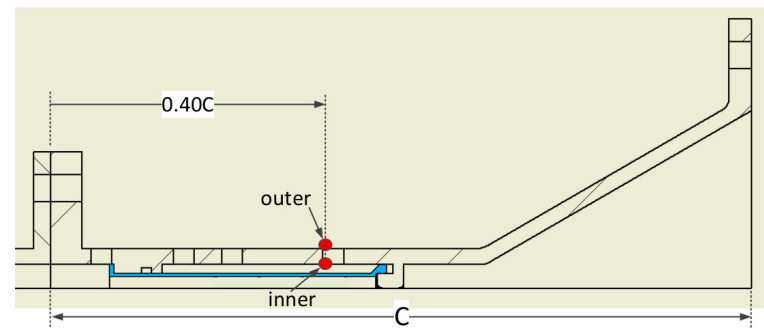

Fig. 7: Cross-section of the engine casing showing the axial position of the thermocouple relative to impingement plate (shaded in blue) and casing

bow set-up captures differences related to buoyancy which may be encountered in an actual engine by placing plates of the same type at the bottom and top of the rig as well as on opposite sides.

Figure 6 shows the thermocouple position relative to the hole/row positions. At each of these positions there are thermocouples spot-welded to the casing inner and outer surfaces as shown in Fig. 7. There are several other thermocouples located over the casing however these positions are not among the impingement hole array therefore will not be used for the purpose of this study. Every second impingement plate has outer thermocouples in the position shown in Fig.s 6 and 7.

The accuracy of the impingement plate manufacture is

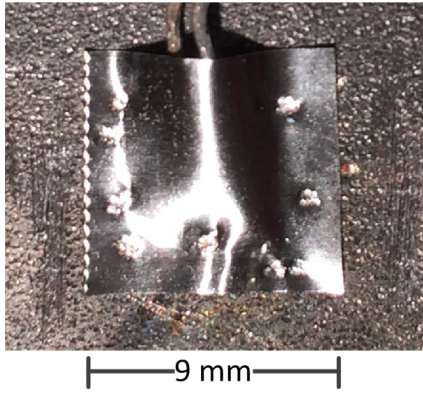

Fig. 8: Thermocouple fixing method to casing surface

important to reduce uncertainty in the HTC calculation in regards to the impinging jet. Twenty plates were manufactured to reduce the error in the $\mathrm{z} / \mathrm{d}$ ratio. If there are fewer plates then the plates are larger and it is more difficult to maintain the dimensional accuracy of the build. The impinging jet is affected by several factors including: length-to-diameter $(\mathrm{L} / \mathrm{d})$ ratio of the hole, the angle of inclination and orientation of the hole, radiusing and/or chamfering of the hole, and flaring of the hole [18]. The current study has concentrated on $1 \mathrm{~mm}$ round holes with an constant $\mathrm{L} / \mathrm{d}$ of 1 , a $90^{\circ}$ angle of inclination and orientation, and no radiusing, chamfering or flaring. The manufacturing effect considered to have the most profound impact on the impinging jet was the consistency of the hole diameter. The effect of increasing or decreasing the hole diameter by a small amount $( \pm 0.05 \mathrm{~mm}$ or 5\%) was assessed by using the Florshuetz et al [15] correlation for a jet array impingement with crossflow. These uncertainties will be quantitatively discussed in Sect. 8.2.

\section{Instrumentation}

The analogue turbine casing is instrumented with K-type thermocouples that have the thermocouple junction affixed to the casing surface by a small piece of spot-welded stainless steel shim (approximately $9 \times 9 \mathrm{~mm}$ square) as shown in Fig. 8. This method was employed to protect the thermocouples from the high air temperatures and jet velocities expected in this region. The presence of the thermocouple junction and shim create an aerodynamic disturbance when in close proximity to impingement jets. This in turn creates an enhanced local HTC. For this reason, the inner casing thermocouple measurement cannot reliably be used during the impingement process. An explicit solution to the heat conduction through a finite wall has therefore been formulated to determine the inner casing wall temperature during the impingement process using outer thermocouple measurements. As explained in the following section, the explicit solution still requires an initial temperature distribution as a boundary condition, hence the inner thermocouple readings immediately prior to the test must be used. At this point, the thermocouple is in a steady-state condition surrounded by stagnant air because the impingement system has not yet been turned on. The outer wall thermocouples, which were instrumented in the same way, are not affected by any locally generated heat transfer enhancement since they are not 


\section{Identification of Heat Transfer Coefficient 5.1 Temperature Distribution}

It was argued earlier in Sect. 4 that using inner thermocouple measurements to determine the HTC may not be representative of the true HTC due to the local enhancement generated by the thermocouple in the vicinity of the impingement jets.

This problem could be avoided if the calculation of HTC were to use outer thermocouples only. Prior to starting the impingement system, a steady state condition is assumed, where the inner surface temperature is at $T_{i}^{0}$, the outer surface temperature is $T_{o}^{0}$ (both shown in Fig. 9) and the temperature distribution across the metal is linear thereby formulated as:

$$
T(x, 0)=T_{i}^{0}+\left(T_{o}^{0}-T_{i}^{0}\right) \frac{x}{l}
$$

The above translates to the distribution on the initial condition $z(x, 0)$ as:

$$
z(x, 0)=T_{i}^{0}-b+\left(T_{o}^{0}-T_{i}^{0}-a l\right) \frac{x}{l}
$$

By making use of the orthogonality of the eigenfunctions of $\psi_{m}$ (as derived in the Appendix) we can compute the coefficients $c_{m}$ using above and (16):

$$
\begin{aligned}
c_{m}= & \frac{1}{\int_{x=0}^{x=l}\left(\sin \left(\beta_{m} x\right)+\frac{k \beta}{h_{1}} \cos \left(\beta_{m} x\right)\right)^{2} d x} \times \\
& \int_{x=0}^{x=l} z(x, 0)\left(\sin \left(\beta_{m} x\right)+\frac{k \beta}{h_{1}} \cos \left(\beta_{m} x\right)\right) d x
\end{aligned}
$$

The time history of the outer thermocouples was extracted from the CHT simulation at the experimental thermocouple location illustrated earlier in Fig. 6. Clearly the representation is more accurate the higher the number of terms. However fundamentally this places additional constraints on the optimisation routine making it less tractable. For this reason, a sensible number of 20 terms was used to give a good match.

\subsection{Numerical Optimisation Approach}

To compute the inner heat transfer coefficient $h_{1}$, a nonlinear optimisation of the time trajectory was conducted using the least squares method which can formally be expressed as follows:

$$
\begin{aligned}
& \left\|T_{\text {outer }} \exp .\left(t_{i}\right)-z\left(l, t_{i}\right)-a l-b\right\|_{2} \\
& \text { s.t.cot }\left(\beta_{m} l\right)=\frac{k^{2} \beta_{m}^{2}-h_{1} h_{2}}{k \beta_{m}\left(h_{1}+h_{2}\right)}
\end{aligned}
$$

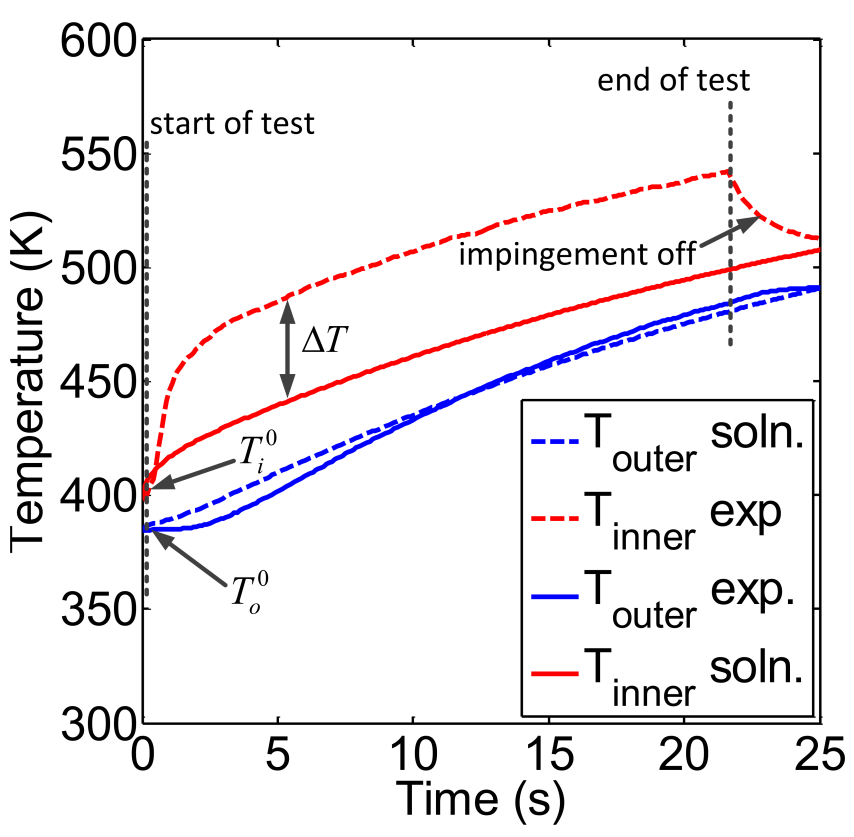

Fig. 9: Example of the comparison of experimental (solid lines) and analytical (dashed lines) casing inner and outer temperatures for Quadrant 1, Plate 1b

where $t_{i}=(0, \Delta t, 2 \Delta t \ldots)$ over the sampled trajectory from the initialisation of the impingement flow.

An assumption is made on the value of $h_{2}$, the outer casing heat transfer coefficient. The value chosen (in the range of $20-50 \mathrm{~W} /\left(\mathrm{m}^{2} \mathrm{~K}\right)$ ) has only a small effect on the computed value of $h_{1}$ and the uncertainty this generates has been quantified in Sect. 8.1.

Figure 9 illustrates the comparison of experimental data and the computed analytical solution for Quadrant 1, Plate $1 \mathrm{~b}$ over the test period. The dotted lines are the measured data using thermocouples. The outer casing temperature agrees very well between the experimental and the analytical solution, indicating that the analytical solution is accurately modelling the real system. The difference between the inner casing temperatures, $\Delta T$, results from the HTC enhancement caused by the stainless steel shim used to protect the thermocouples instrumented on the inner casing surface, explained in Sect. 4. Hence the decision to not use the inner thermocouple measurements for the HTC calculation is justified by the erroneous increase in temperature of up to $50 \mathrm{~K}$.

\section{3-D Numerical Modelling of Impingement System 6.1 Steady RANS Model of Preliminary Impingement Designs}

In order to down-select two effective impingement designs based on the criteria outlined in Sect. 3, a steady-state numerical model was generated of the eight impingement arrays from Tab. 1. The model consisted of a three-dimensional $90^{\circ}$ sector of the annulus derived from the CAD model of the rig. Since there are four offtakes, the flow was considered to be symmetric about the offtake axes. Five $18^{\circ}$-plates were modelled as part of the sector. As seen in Fig. 10, the inlet 
of the computation domain was set downstream of the bullet nose, while the domain exit was set downstream of the impingement plates. The offtake pipe was also modelled, but with a sufficient length so that its exit will experience a uniform flow, thus aiding in solution stability and convergence. The ANSYS CFX v15.0 flow solver was used to perform the steady-state analysis using the RANS model. Buoyancy was neglected in this case because the purpose of this analysis was mainly to assess the performance of the impingement system. The flow was considered to be turbulent based on the vessel Re and the k- $\omega$ SST turbulence model was used with the wall-function approach in the near wall region where the values of $y+$ at the inside surface of the casing were maintained to be less than 5. The ideal gas model was used as the equation of state for the steady RANS as well as the subsequent conjugate heat transfer model described in the following section. The mass flow rate at the offtake was fixed in all cases, which allowed a direct comparison of the effectiveness of each impingement array design, from which Plates $1 \mathrm{~b}$ and $2 \mathrm{~b}$ were identified as the most advantageous in terms of steady-state HTC delivered to the casing.

\subsection{Unsteady Conjugate Heat Transfer (CHT)}

The unsteady CHT model was used to analyse the transient thermal response of the metal casing using the Plates $1 \mathrm{~b}$ and $2 \mathrm{~b}$ impingement arrays in order to compare with the experimental results. This was done to assess the capability of the numerical tools to predict heat transfer coefficients for annular casing impingement arrays and also help to estimate some of the uncertainties associated with instrumentation of the experimental facility using the resulting spatially resolved temperature maps from the simulation.

Since the experimental setup used a rainbow setup with plate 1b in Q1 and Q3 and plate 2b in Q2 and Q4 (shown earlier in Fig. 5), the numerical model also followed this setup, where the $90^{\circ}$ sectors Q1 and Q2 were modelled separately. The offtake was set up to be near the edge of the $90^{\circ}$ sector rather than the centre to be consistent with the experimental model.

The models for the plates $1 b$ and $2 b$ were meshed in ANSYS Mesher v15.0 using tetrahedral elements and inflation layers to model the boundary layer on the inside surface of the casing. The casing was modelled as a solid shown in Fig. 10. The fluid domains for plates $1 b$ and $2 b$ had a total of approximately 35 million elements each, while the solid domains (also shown in Fig. 10), had approximately 3.5 million elements each. The impingement jets were modelled as discrete holes with 10-15 elements across each hole. Proximity refinement was applied to the region of the inner casing surface directly above the holes in order to capture the impingement effect, as seen in Fig. 11(a).

The ANSYS CFX v15.0 flow solver was used to perform the conjugate heat transfer analysis. Firstly, the flow through the fluid domain was established by simulating the steady state CFD at engine conditions, provided in Tab. 2. The value of $\dot{m}$ corresponds to the $90^{\circ}$ sector.

The conjugate heat transfer method was then used to

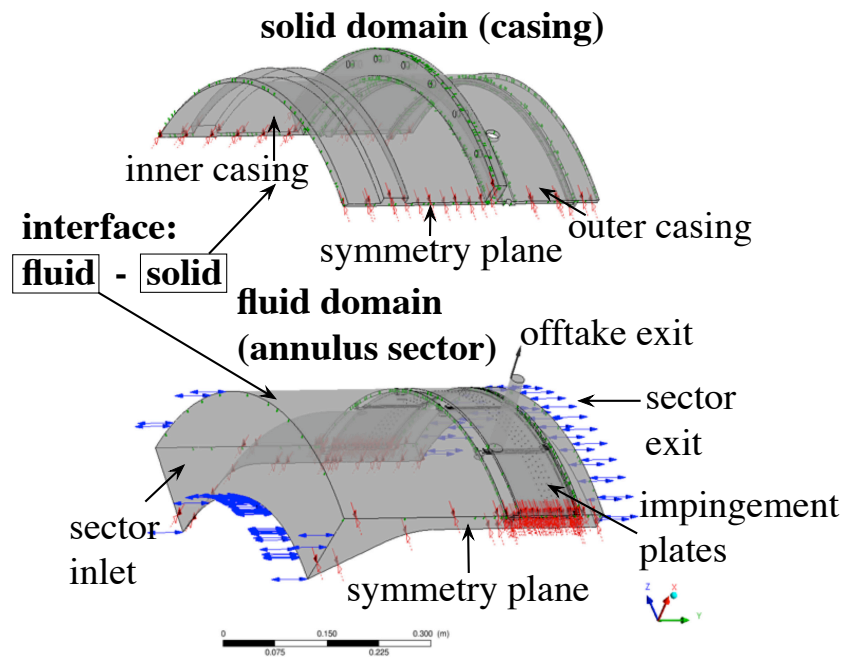

Fig. 10: Computational domain of impingement system (quarter sector)

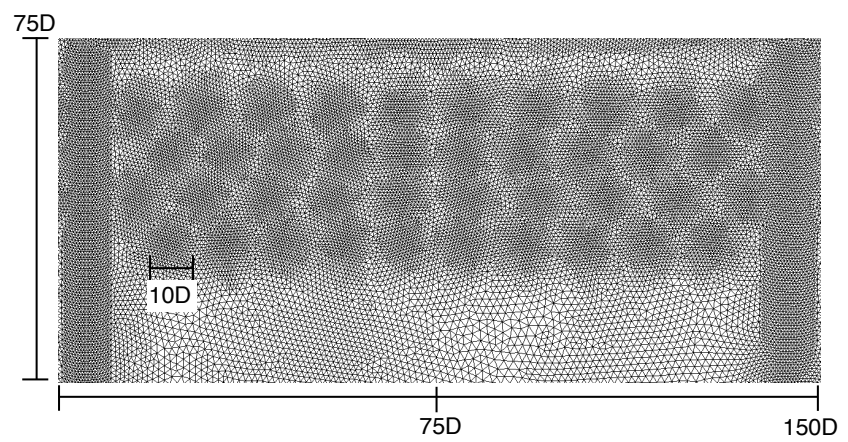

(a)

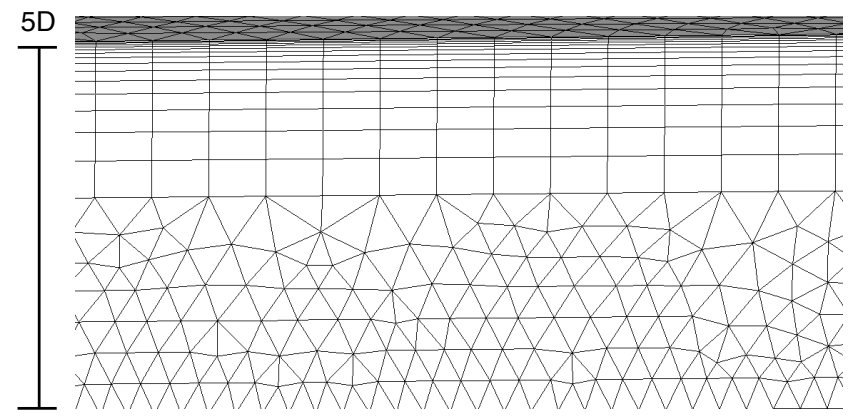

(b)

Fig. 11: Computational grid for plate 2b: (a) fluid side of fluid-solid interface on inner casing above impingement holes and (b) symmetry surface with 15 inflation layers generated from inner surface of casing

resolve the conduction through the metal casing, which was modelled as stainless steel AISI 316 with a density of $7960 \mathrm{~kg} / \mathrm{m}^{3}$ and a temperature-dependent thermal conductivity and specific heat capacity. The initial temperature of the casing was set to $391 \mathrm{~K}$, resulting in a delta temperature of $185 \mathrm{~K}$ relative to the inlet gas temperature, $\mathrm{T}_{i}$. The outside 
Table 2: Boundary conditions for fluid and solid $90^{\circ}$-sector domain for both impingement array designs

\begin{tabular}{ll}
\hline $\mathrm{T}_{i}$ & $576 \mathrm{~K}$ \\
\hline $\mathrm{p}_{i}$ & $1.14 \mathrm{MPa}$ \\
\hline$\dot{m}$ & $0.0866 \mathrm{~kg} / \mathrm{s}$ \\
\hline $\mathrm{T}_{\text {metal }}$ & $391 \mathrm{~K}$ \\
\hline
\end{tabular}

temperature was set to $373 \mathrm{~K}$ while the outer surface of the casing was set to have an estimated HTC of $20 \mathrm{~W} / \mathrm{m}^{2} \mathrm{~K}$ to account for the slight cooling effect from the outer cavity. The heat fluxes were interpolated across the dissimilar meshes on the fluid-solid interface (the inside surface of the casing) and the conservation of energy equation was applied to the solid domain to account for heat transport. The conjugate heat transfer was performed transiently, where the time step was set to $0.02 \mathrm{~s}$ and the second order backward Euler transient scheme was applied. The convergence and accuracy of conjugate heat transfer modelling is dependent upon the number of solver iterations required within each time step. In this case, the number was set to 50 which significantly increases the computational time required but also decreases the numerical error in the resulting solution. Resolving $2 \mathrm{~s}$ of data required approximately two weeks of simulation time across 16 processors for each plate configuration ( $1 \mathrm{~b}$ and $2 \mathrm{~b}$ ).

For the purpose of comparison, it is useful to plot nondimensional temperature $\left(\theta^{*}\right)$ as a function of Fourier number $F o=k t /\left(\rho c l^{2}\right)$ where non-dimensional temperature is formulated as follows:

$$
\theta^{*}=\frac{T-T_{0}}{T_{f}-T_{0}}
$$

and where $T$ is the metal temperature at time $t, T_{0}$ is the average metal temperature at the beginning of the transient test period, and $T_{f}$ is the initial fluid driving temperature at the beginning of the transient test period.

Figure 12 shows snapshots of the impingement area on the inner surface of the casing (solid interface) at the same Fourier number $(\mathrm{Fo}=0.2)$ for the plate $1 \mathrm{~b}$ and $2 \mathrm{~b}$ configurations from the unsteady CHT simulation. The location of the offtake for both configurations is between the two plates at $10^{\circ}$ and $-10^{\circ}$. The suction effect of the offtake is a source of circumferential non-uniformity across the $90^{\circ}$-sector since it reduces the temperature between $\phi= \pm 9-27^{\circ}$ for both plates; however, this effect is more pronounced for Plate $2 b$, since the first row of holes at $\mathrm{Y} / \mathrm{d}=42$ is closer to the offtake than the first row of holes on Plate 1b. Since both plates were run at a constant mass flow rate condition set at the offtake exit, the jet velocities through the holes in Plate $1 \mathrm{~b}$ will be higher and result in higher stagnation temperatures, visible

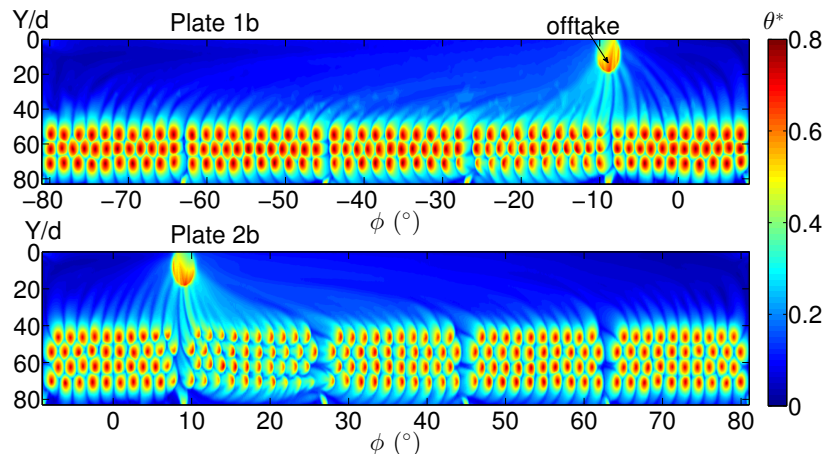

Fig. 12: Snapshot of non-dimensional temperature $\theta^{*}$ on metal inner surface at $\mathrm{Fo}=0.2$ for plates $1 \mathrm{~b}$ and $2 \mathrm{~b}$ from unsteady CHT simulation

\section{in Fig. 12.}

In the experimental setup, there are various sources of circumferential non-uniformities and leakage paths which the numerical analysis would not be able to capture without a considerably more complex computational model and mesh. However, since the numerical analysis allows a comprehensive view of the spatially resolved heat transfer map, it is extremely useful in helping to determine the uncertainty due to various factors such as exact thermocouple location and lack of thermocouples in spanwise location.

The position of the thermocouple junctions relative to the impingement jet on the outer casing will effect the casing temperature response (i.e. if the thermocouple junction is not between impinging jets then the temperature gradient will be greater). The effect of an incorrectly positioned junction has been investigated numerically and will be quantitatively discussed in Sect. 8.1.

\section{Results}

\subsection{Uniformity of Case Heating}

The rig mechanical design is such that there is nonuniformity in how the rig behaves, resulting in circumferential temperature non-uniformities. These effects are likely to be due to a combination of several factors including:

1. Non-uniformity of sealing across the circumference of the impingement plates,

2. Some buoyancy effects due to low speed flow and the fact that the metal is not thermally soaked,

3. Non-uniformity of the sealing between the outer pressure vessel and the inner pressure vessel,

4. The proximity of the outer thermocouples to the jets, which could result in different observed temperature gradients,

5. Other features of the engine that may cause heat loss.

Since the rig has been designed to model a generic aeroengine one would also expect non-uniformities to be present in an aero-engine. Obviously, as long as it is not extreme, some temperature non-uniformity can be tolerated. The important aspect is to demonstrate that the temperature differences are not too large. Several tests were conducted to 


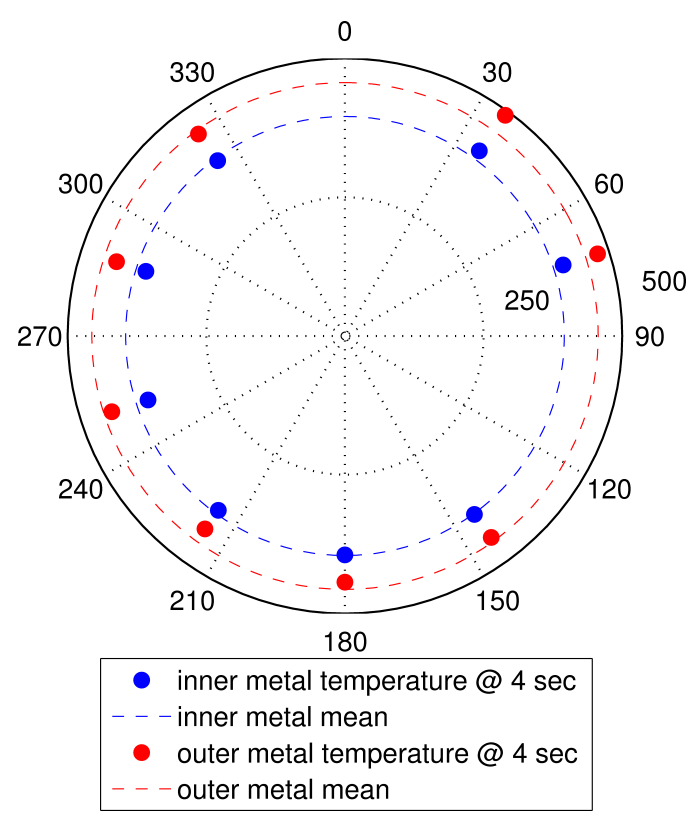

Fig. 13: Circumferential temperature uniformity for inner and outer thermocouple locations. Circumferential scale is in degrees and radial scale is in Kelvin.

demonstrate repeatability however for the purposes of clarity, data after 4 seconds of test time for one particular test is shown. The inner and outer metal temperatures are plotted in Fig. 13 to illustrate the temperature non-uniformity for the current tests. The mean temperature on each surface is shown as dashed lines for further clarity. The uncertainty for each measurement point is $\pm 4 \mathrm{~K}$ which is based on the instrument and location uncertainties discussed in Sect. 8.1. In this facility there is cooling air entering the outer cavity at the lower left and the temperatures are cooler in this quadrant. This air exits at the upper right when it is at a higher temperature explaining the higher temperatures in this quadrant. Such features as this are present in actual engines and must be given careful consideration at the design stage.

Table 3: Circumferential variation in casing temperature increase after 4 seconds of test time

\begin{tabular}{llll}
\hline $\begin{array}{lll}\text { Thermo- } \\
\text { couple }\end{array}$ & $\Delta \mathrm{T}$ & $(\mathrm{abs}, \mathrm{K})$ & $(\%)$ \\
location & $(\mathrm{K})$ & & \\
\hline \hline Inner & 75.8 & 19.2 & 25.3 \\
Outer & 13.1 & 1.66 & 12.7 \\
\hline
\end{tabular}

In order to quantify the uniformity of case heating, the

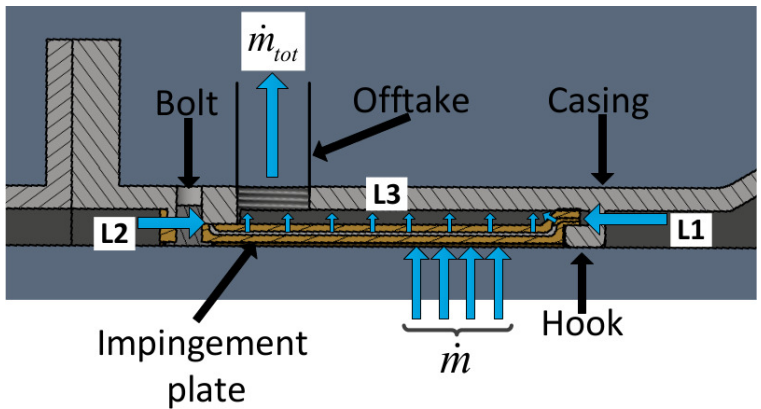

Fig. 14: Schematic of the main flows entering the impingement cavity. L1, L2 and L3 are leakage flows, $\dot{m}$ is the total impingement flow and $\dot{m}_{t o t}$ is the total flow out of 4 offtake pipes.

mean temperature rises in four seconds of test time were compared to the variation from the mean. The variation at two standard deviations from the mean was determined for the inner and outer thermocouple locations over the full circumference. Table 3 shows the mean increase in temperature $(\Delta \mathrm{T})$ of the casing at the thermocouple locations, and the two sigma variation as an absolute value and as a percentage.

There are significant variations in terms of percentage however the absolute variation for both inner and outer thermocouple locations is less than $\pm 20 \mathrm{~K}$. This variation may be reflected in the HTCs seen in the two plate configurations tested and the affects will be discussed further in Sect. 9.

\subsection{Total Flow Consumption of the System}

The impingement plates are mounted to the casing at the downstream end by being inserted into a hook on the casing and then secured to the casing at the upstream end by a bolt (Fig. 14). The sealing arrangement indicated in this figure employs braided seals in the hook recess and in a fullcircumference O-ring groove near the bolts; and metal strip seals between plates which create the leakages L1, L2 and L3 respectively. Tolerances associated with additive manufacture segment pieces and general machining of the rig will contribute to leak paths that will produce significant leakage probably higher than those seen in an actual engine. It is however still possible to get an understanding of the leakages expected in an engine as a function of pressures and temperatures and offer improvements to the system design that will reduce leakage.

The leakage around the seals of the impingement plates has a large bearing on the effectiveness of the impingement system. The total mass flow out of the four offtake pipes, ( $\dot{m}_{t o t}$ in Fig. 14), is measured by incorporating orifice plates at the control valves and ensuring these plates remain in a choked state. These orifice plates have been calibrated and allow the mass flow rate to be determined with an uncertainty of $\pm 4.45 \%$. The impingement flow $(\dot{m})$ uncertainty is dictated by the uncertainty in the pressure ratio across the plates and the discharge coefficient. The accuracy of the pressure measurement is restricted by the accuracy of the pressure 


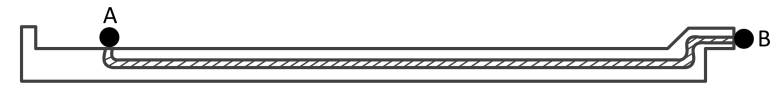

(a.)

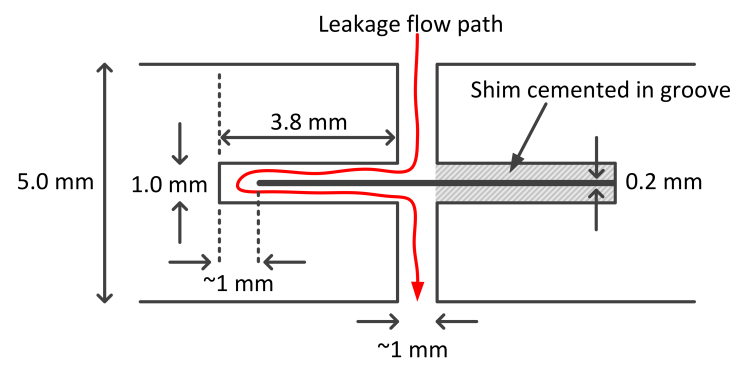

(b.)

Fig. 15: Sketch of the seal arrangement between impingement plates and the leakage paths L1, L2, L3, (a.) close-up cross-sectional view showing the shim seal within the groove looking axially, (b.) cross-section of full plate showing the braided seal positions A and B looking circumferentially

transducers in the annulus and under the impingement plates. The pressure transducers need to have a high range in order to measure the working section pressures. However, the pressure drop over the plates is relatively small such that the uncertainty in the instrument will contribute significantly to the uncertainty in the pressure ratio. A discharge coefficient of 0.9 has been assumed for the flow through the plates based on McGreehan and Schotsch [19]. A summary of calculated leakages as a function of the temperature and pressure during a typical test for the full circumference and also for each quadrant is shown in Tab. 4.

Table 4: Leakages as a function of pressure and temperature

\begin{tabular}{llllll}
\hline & $\begin{array}{l}\text { All } \\
\text { quads }\end{array}$ & $\begin{array}{l}\text { Q1 } \\
\text { Plate } \\
1 \mathrm{~b}\end{array}$ & $\begin{array}{l}\text { Q2 } \\
\text { Plate } \\
2 \mathrm{~b}\end{array}$ & $\begin{array}{l}\text { Q3 } \\
\text { Plate } \\
1 \mathrm{~b}\end{array}$ & $\begin{array}{l}\text { Q4 } \\
\text { Plate } \\
2 \mathrm{~b}\end{array}$ \\
\hline \hline P ratio & 1.02 & 1.02 & 1.02 & 1.02 & 1.02 \\
\hline $\mathrm{T}_{\text {fluid }}$ & 302.7 & 316.2 & 300.5 & 296.1 & 298.2 \\
\hline$\dot{m}_{\text {tot }}(\mathrm{kg} / \mathrm{s})$ & 0.752 & 0.187 & 0.185 & 0.190 & 0.194 \\
\hline$\dot{m}+L 3(\mathrm{~kg} / \mathrm{s})$ & 0.338 & 0.079 & 0.086 & 0.077 & 0.096 \\
\hline $\mathrm{L} 1+\mathrm{L} 2$ & 0.414 & 0.108 & 0.099 & 0.113 & 0.098 \\
$(\mathrm{~kg} / \mathrm{s})$ & & & & & \\
\hline \hline \% leakage & 55.1 & 57.8 & 53.5 & 59.5 & 50.5 \\
\hline
\end{tabular}

From Tab. 4 it is clear that the total leakage is sizeable and that it depends on the quadrant and impingement plate configuration. Plate 1b in Q1 and Q3 have fewer holes and therefore a smaller impingement mass flow rate but they exhibit the highest leakage.

An estimation of the leakage between the seals has been made by assuming that the leakage discharges from a slot between the plates. For the leakages L1 and L2, the crosssectional area is assumed to be very small. The crosssectional area of this slot is calculated by determining the length between braided seals A and B in Fig. 15 (a.) and multiplying by an assumed leakage gap of $25 \mu \mathrm{m}$. For the leakage from L3, the cross-sectional area of this slot is calculated by determining the cross-section of the seal groove, subtracting the area of the shim seal (seal groove length times shim thickness) and then dividing by two. The shim seal groove and the dimensions are shown in Fig. 15 (b.). Based on these calculations for leakages L1 - L3 and assuming a discharge coefficient for a slot is $0.6[20,21]$ the percentage of leakage for plates $1 \mathrm{~b}$ and $2 \mathrm{~b}$ is $62.5 \%$ and $53.6 \%$ respectively. These amounts are in close agreement with the figures cited in Tab. 4.

Although the leakage could be improved by simply reducing the number of impingement plates so that there are fewer joins, this is not always possible in an engine configuration. More practically, the seal between plates could be improved significantly from the shim seal employed in this study.

\section{Uncertainty and Sensitivity in HTC \\ 8.1 Uncertainty in HTC}

The uncertainties in the experimental measurements need to be quantified in order to have confidence that the facility is producing accurate data that can be reliably compared to numerical results. The following areas have been identified in the previous sections as having a significant contribution to the uncertainty in HTC:

1. Fluid temperature in the annulus at the impingement plate position - this will contribute to an uncertainty in the HTC calculation since this uses the initial value of the fluid temperature.

2. Metal temperature of the outer surfaces due to the position of the thermocouple junction in relation to the impingement jet. The time history of the outer temperature measurements was used in the explicit solution in Sect. 5 to calculate the HTC.

3. Effect of a single measurement point under each plate. There could be an unknown spatial metal temperature uncertainty that could be unaccounted for. There could be thermal inertias in different positions under the plate that will not be captured, once again, affecting the temperature rise and therefore inference of the HTC.

The uncertainties listed above have been quantified and these values are listed in Tab. 5. One other area of uncertainty, material property variation of the impingement plates, was investigated and subsequently neglected as a significant source of uncertainty. The casing and impingement 


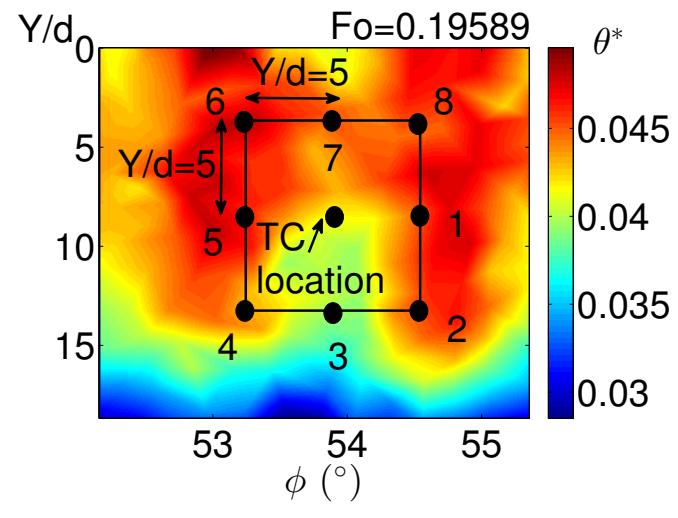

(a) Temperature map of outer casing region surrounding thermocouple location with variation of location by $\pm \mathrm{Y} / \mathrm{d}=5$ in each direction

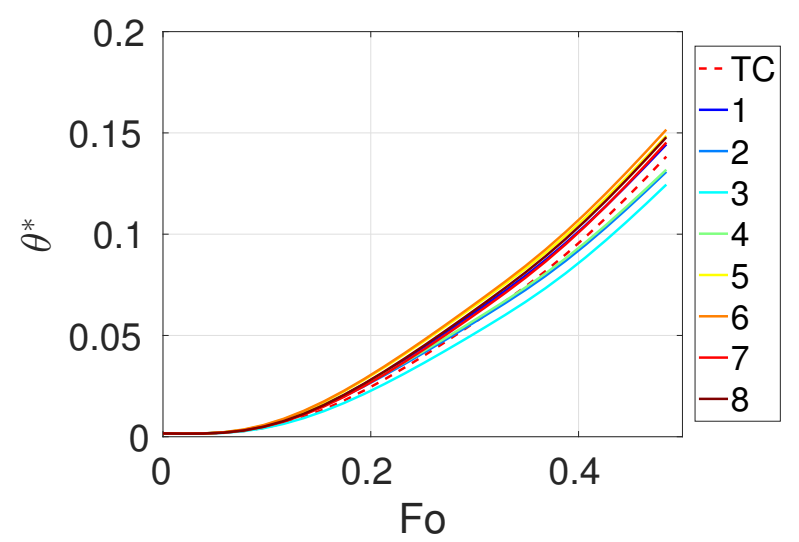

(b) Time history of thermocouple $\theta^{*}$ and Locations 1-8 illustrated in (a), where a $2.4 \mathrm{~K}$ difference in temperature is observed between TC and Location 6 at $\mathrm{Fo}=0.48$

Fig. 16: Estimation of thermocouple location uncertainty using result of unsteady CHT simulation of Plate $2 \mathrm{~b}$ at $\mathrm{Fo}=0.48$

plates have been manufactured with materials specified in the British Standards $[14,17]$ and as such the material properties were assumed to be isotropic and of insignificant variation. The material properties for these materials were taken from the ASM Handbook [22].

The uncertainty in the measurement of the fluid and metal temperatures due to thermocouple uncertainty of $\pm 2.5 \mathrm{~K}$ can be directly applied to the HTC calculation to determine the effect. In both cases this appears to have only a small influence.

In order to estimate the uncertainty in $\mathrm{T}_{\text {metal }}$ due to the location of the thermocouple, the results from the unsteady CHT analysis were used. As illustrated in Fig. 16(a), the location of the thermocouple was set according to the experimental setup in Fig. 6 on the outer surface of the casing. Eight points were chosen in a square around the thermocouple with distance $\mathrm{Y} / \mathrm{d}=5$ (where $\mathrm{d}$ is the hole diameter). As visible from Fig. 16(a), the shape of the jet is considerably smeared out by the time the heat is conducted through the thickness of the casing. This results in the different time histories of non-dimensional temperature shown in Fig. 16(b), where the maximum temperature would occur at Location 6.
Table 5: Uncertainties of measurements on the calculation of HTC

\begin{tabular}{llcc}
\hline $\begin{array}{l}\text { Uncertainty } \\
\text { parameter }\end{array}$ & $\begin{array}{c}\text { Absolute value } \\
\text { of parameter }\end{array}$ & $\begin{array}{c}\text { Percentage } \\
\text { of HTC }\end{array}$ \\
\hline \hline 1. & $\mathrm{T}_{\text {fluid }}$ & $\pm 2.5 \mathrm{~K}$ & \pm 1.7 \\
\hline \hline 2. & $\mathrm{T}_{\text {metal }}$ & $\pm 2.5 \mathrm{~K}$ & \pm 0.26 \\
& - instrument & $\pm 5 \mathrm{~mm}$ & \pm 4.15 \\
& - location & $+0.2 \mathrm{~K}$ & \pm 0.32 \\
\hline \hline 3. & Single measurement & & \\
\hline \hline 4. & Casing exterior & $+30 \mathrm{~W} /\left(\mathrm{m}^{2} \mathrm{~K}\right)$ & \pm 6.1 \\
\hline & surface HTC $\left(h_{2}\right)$ & \pm 7.58 \\
\hline \hline
\end{tabular}

For this calculation, only Plate $2 \mathrm{~b}$ was simulated up to $5 \mathrm{sec}-$ onds of realtime, as the variation in jet locations is similar across the 2 plate designs (see jet spacings in Tab. 1). After 5 seconds $(\mathrm{Fo}=0.48)$ the temperature rise becomes linear and the temperature difference between locations would remain constant. The maximum temperature difference was $2.4 \mathrm{~K}$ and when this difference was added to the temperature inputs of the explicit solution calculation, an average uncertainty of $\pm 4.15 \%$ was obtained as shown in Tab. 5 . This method highlights the benefit of the 3-D, unsteady, conjugate heat transfer analysis simulated at identical operating conditions as the experiment, in terms of better quantifying the limitations in instrumentation.

One of the other limitations of the instrumentation was the use of one location for each plate for the thermocouples, placed on the outer surface of the casing. This was done due to the restrictions on space between the impingement plate and casing and the difficulties of routing all of the thermocouples through a sufficiently large gap through the insulation of the pressure vessel. The uncertainty for having one thermocouple location was estimated using a similar method as the thermocouple location uncertainty calculation above. The average of the outer casing metal temperature in the $90^{\circ}$ sector was calculated using the exact thermocouple location as the experimental setup. Another thermocouple location was then added 16 diameters upstream of the current location on the outer surfaces of the casing model. The maximum temperature difference is $0.2 \mathrm{~K}$ which results in an uncertainty in HTC of $\pm 0.32 \%$.

The final uncertainty considered was the estimate of the casing exterior surface heat transfer coefficient. Values of $20-50 \mathrm{~W} /\left(\mathrm{m}^{2} \mathrm{~K}\right)$ were evaluated in a sensitivity analysis by setting different values in the explicit solution calculation used to determine $\left(h_{1}\right)$. Maximum variations of $5.5 \%$ for 
plate $1 \mathrm{~b}$ and $6.6 \%$ for plate $2 \mathrm{~b}$ at $50 \mathrm{~W} /\left(\mathrm{m}^{2} \mathrm{~K}\right)$ were recorded. This resulted in an average uncertainty of $\pm 6.1 \%$ as shown in Tab. 5.

With the assumption that the uncertainties are independent of each other, the total uncertainty in the HTC measurement has been determined to be $\pm 7.58 \%$ using the root sum squared method.

\subsection{Sensitivity in HTC}

Once the uncertainty associated with all of the input parameters to the HTC calculation from Sect. 5, such as $T_{\text {metal }}$, $T_{\text {fluid }}$, single measurement and $h_{2}$ have been calculated, it is also important to understand the sensitivity of the HTC to other parameters in the experiment that are assumed to be constant but in reality, they also have uncertainties associated with them. These parameters have been identified as:

1. Manufacturing accuracy of the impingement plates. There is uncertainty associated with the size of the holes which will influence the jet impingement.

2. The impingement mass flow rate uncertainty will be dictated by uncertainties in calculation parameters including pressure ratio uncertainty due to error in the pressure transducer measurement, and fluid temperature uncertainty in the annulus.

The sensitivities listed above have been quantified and these values are listed in Tab. 6. These sensitivities are assumed to be independent in order to apply the root sum squared method.

Table 6: Sensitivity of measured parameters that influence HTC

\begin{tabular}{llcc}
\hline & $\begin{array}{l}\text { Uncertainty } \\
\text { parameter }\end{array}$ & $\begin{array}{c}\text { Absolute value } \\
\text { of parameter }\end{array}$ & $\begin{array}{c}\text { Percentage } \\
\text { of HTC }\end{array}$ \\
\hline \hline 1. & $\begin{array}{l}\text { Manufacturing } \\
\text { (hole size) }\end{array}$ & $\pm 0.05 \mathrm{~mm}$ & \pm 8.5 \\
\hline \hline 2. & $\dot{m}$ & & \\
& - Pressure ratio & 0.02 & \pm 15.2 \\
& $-\mathrm{T}_{\text {fluid }}$ & $\pm 2.5 \mathrm{~K}$ & \pm 0.15 \\
\hline \hline & Total (RSS method) & & \pm 17.4 \\
\hline \hline
\end{tabular}

The Florschuetz et al [15] correlation for a jet array impingement with crossflow was used to estimate the sensitivity of the HTC to the aforementioned parameters. If the hole diameter is increased or decreased the resultant change in HTC can be observed. The change in HTC has been determined

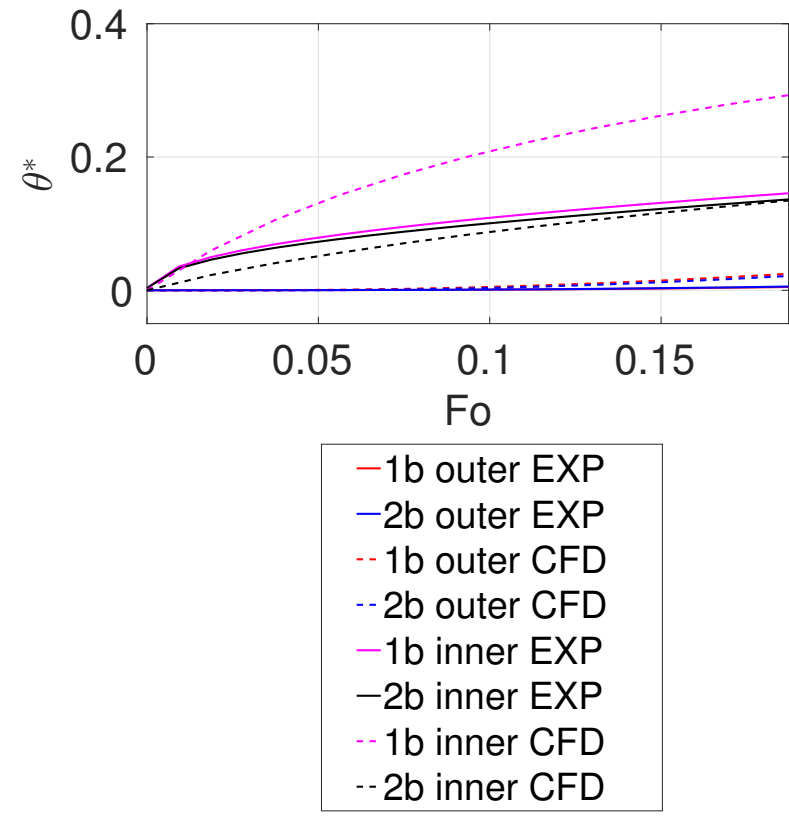

Fig. 17: Non-dimensional temperature rise with respect to Fourier number for plates $1 b$ and $2 b$ on the inner and outer surface of the casing, with comparison of experimental and unsteady CHT simulation

for a small change in hole diameter $( \pm 0.05 \mathrm{~mm}$ or $\pm 5 \%)$. This has introduced a moderate change in the HTC value.

The sensitivity in mass flow rate is dependent on the measurement of pressure ratio and the fluid temperature measurement. The fluid temperature measurement imparts a very small change in HTC through the uncertainty in the thermocouple. The pressure ratio sensitivity is much more significant due to the greater sensitivity of jet velocity to change in pressure ratio. The uncertainty in the pressure transducer is \pm 0.117 bar which would result in the pressure ratio increasing from 1.04 to 1.06 if applied as a minus to the pressure measurement under the plate and an addition to the pressure in the annulus. This change in turn causes a large increase in jet velocity and a large increase in mass flow rate through the impingement jet holes.

The resultant value of sensitivity, calculated using the RSS method, provides a quantitative measure of factors that can have a large impact on the performance of this system.

\section{Comparison of Experiment and Numerical Results}

The non-dimensional temperatures for both experimental and numerical results are shown in Fig. 17. The nondimensional time was plotted until $\mathrm{Fo}=0.19$ (real time of 2 seconds) for comparison purposes, which was limited by the extensive numerical cost of running both plate simulations for 5 seconds. The thermal response of the experimental system is visible with the rise of $\theta^{*}$ at the inner casing surface over that time period. The outer surface temperatures shown for both experimental and numerical data are directly ob- 


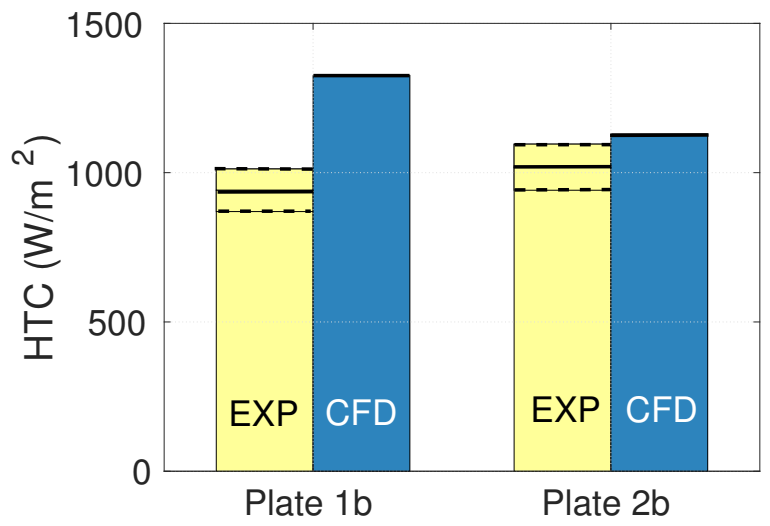

Fig. 18: Experimental HTCs compared to numerical HTCs for Plates $1 b$ and $2 b$ with error bars

tained from both respective analyses. The inner surface temperatures for the experimental results are derived from the explicit solution calculation using the inputs of outer temperature rise from the experiments while those for the numerical results are taken directly from the CFD simulation. The inner temperatures for Plate $2 \mathrm{~b}$ are in good agreement across the experimental and numerical results. The numerical inner temperature for Plate $1 \mathrm{~b}$ is significantly higher than the experimental result due to leakage in the experimental system which will be discussed below.

The difference in the gradient of the outer wall temperatures can be explained by the fact that the outer cavity HTC $\left(h_{2}\right.$ in Fig. 19) is slightly higher than anticipated in the experiment due to the convecting cells that form in the stagnant air in the outer cavity of the vessel. The outer HTC in the CHT simulation was set to be a conservative value of $20 \mathrm{~W} / \mathrm{m}^{2}$, whereas the experiment potentially sees a slightly higher value and also varies circumferentially. In future work, the value of the outer cavity temperature and therefore the value of $h_{2}$ will need to be measured more accurately to reduce the uncertainty to the overall HTC.

The inner surface temperature rise of Plate $1 \mathrm{~b}$ is predicted to be higher than that of Plate $2 b$ by the numerical analysis which also results in a higher predicted HTC. The comparison of the inner HTCs due to impingement for each plate design is shown in Fig. 18. The error bar of $\pm 7.58 \%$ has been added to the experimental values as dashed lines. The HTCs have been averaged across Quadrants 1 and 3 for Plate $1 \mathrm{~b}$ and Quadrants 2 and 4 for Plate 2b. The overall values of the HTCs are in good agreement across the experimental and numerical results for Plate $2 \mathrm{~b}$. The experimental HTC for Plate $1 b$ is $29 \%$ lower and Plate $2 b$ is $9.8 \%$ lower than the numerical HTCs.

The reason for the relatively large difference in Plate $1 b$ impingement heat transfer can be inferred from the leakage flows discussed earlier in Tab. 4. Quadrants 1 and 3 that house the $1 \mathrm{~b}$ plate design experience a higher leakage flow than Quadrants 2 and 4 that house the 2 b plate design. This decreases the impingement mass flow rate through the holes and therefore the resulting HTC to the casing. The unsteady CHT simulation assumes an ideal system with no gaps or leakages, hence both plate designs experience an identical mass flow rate through the holes, therefore Plate $1 \mathrm{~b}$, which has fewer holes and therefore a smaller flow area, experiences a higher jet velocity compared to Plate $2 \mathrm{~b}$. This results in a numerically predicted HTC that is $17 \%$ higher for the Plate $1 \mathrm{~b}$ design relative to Plate $2 \mathrm{~b}$. This ideal scenario does not occur in the experiment, nor would it occur in a real engine. The mass flow rate available to a secondary air system will always have to be minimised in a real engine. The numerical simulation shows that for a given mass flow rate, Plate $1 \mathrm{~b}$ is more advantageous. However, the experiment shows that in an engine-representative environment, various factors such as circumferential non-uniformity, seen earlier in Fig. 13, and leakage flows, shown in Tab. 4, dominate the effectiveness of each design. However, the numerical analysis was beneficial in quantifying the limitations of the instrumentation. Therefore, it can be concluded that both the experimental and conjugate heat transfer analysis are equally valuable in designing an effective impingement array that seeks to speed up the thermal response of an engine casing.

\section{Conclusion}

The THTF was used to investigate the transient thermal response of a full-scale, 3D, engine representative casing at typical cruise conditions. An annular impingement array was designed and successfully implemented in the THTF to enhance the HTC delivered to the casing in order to speed up its thermal response. Two such impingement array designs down-selected from a set of eight designs were tested in a rainbow set around the annulus and their relative performance was assessed.

Temperature non-uniformities were assessed circumferentially and it was noted that although Q2 and Q4 use the same plate configuration, Q2 had significantly higher temperatures. This may be due to entry and exit of cooling in the outer cavity and the effects of similar features on an actual engine should be carefully considered.

The uncertainty analysis utilised a combination of empirical and numerical methods to estimate the uncertainty associated with the HTCs. This resulted in an experimental uncertainty in HTC of $\pm 7.58 \%$ and a calculated sensitivity of $\mathrm{HTC}$ of $\pm 17.4 \%$.

The HTC delivered to the casing due to impingement was inferred from the outer wall temperature measurements and the explicit solution for 1-D heat conduction through a finite wall.

A numerical model using the conjugate heat transfer method was compared to the experimental results with the aim of assessing its capacity to predict the dynamic temperature response and HTCs for future annular impingement array designs, as well as help estimate the uncertainties associated with limited instrumentation in the experiment. The same approach was used to calculate the HTC from the unsteady CHT simulation by extracting the transient temperatures at the thermocouple locations on the outer wall of the 
solid domain. The absolute values of HTC during the experimental tests were lower than the numerically predicted values for Plate $1 \mathrm{~b}$ (within 29\%) and agreed well with Plate $2 \mathrm{~b}$ (within 9.8\%). The difference in performance of Plate $1 \mathrm{~b}$ is likely due to the large amount of leakage on the experimental tests which has not been simulated numerically. Leakage of air around the plate seals which is not impinging on the casing but is contributing to a significant cross-flow effect has resulted in lower HTCs. The leakage could be improved by simply reducing the number of impingement plates so that there are fewer joins or by improving the seal itself.

Both the experimental and numerical approaches predicted differences in which of the two designs was more effective; however, advantages and limitations were identified in both approaches. The combined experimental and numerical study shows the significance of analysing the full annulus at engine representative conditions and the benefit of an impingement array to potentially speed up casing response for future engines.

\section{Acknowledgements}

The authors would like to thank Rolls-Royce plc and Innovate, UK for financial support of this project. We would also like to thank Rolls-Royce plc for technical support.

\section{References}

[1] Lattime, S. B., and Steinetz, B. M., 2002. Turbine engine clearance control systems: Current practices and future directions. Tech. rep., NASA Technical Memorandum, NASA/TM-2002-211794.

[2] Denton, J., 1993. "Loss mechanisms in turbo machines". J. Turbomach, 115, pp. 621-656.

[3] Han, J., Dutta, S., and Ekkad, S., 2000. Gas Turbine Heat Transfer and Cooling Technology, 2nd ed. Taylor and Francis. ISBN: 15603284.

[4] Ameri, A. A., and Bunker, R. S., 1999. "Heat transfer and flow on the first-stage blade tip of a power generation gas turbine: Part 2 - simulation results". J. Turbomach, 122(2), pp. 272-277.

[5] Mayle, R., and Metzger, D., 1982. "Heat transfer at the tip of an unshrouded turbine blade". In Proc. Seventh Ins. Heat Transfer Conf, Hemisphere Pub.

[6] Bunker, R. S., Bailey, J. C., and Ameri, A. A., 1999. "Heat transfer and flow on the first stage blade tip of a power generation gas turbine: Part 1 - experimental results”. In ASME 1999 International Gas Turbine and Aeroengine Congress and Exhibition, Vol. 3: Heat Transfer; Electric Power; Industrial and Cogeneration.

[7] Kwak, J. S., Ahn, J., and Han, J.-C., 2004. "Effects of rim location, rim height, and tip clearance on the tip and near tip region heat transfer of a gas turbine blade". International Journal of Heat and Mass Transfer, 47(26), p. 56515663.

[8] Choi, M., Tapanlis, O., Lewis, L., Ciccomascolo, C., and Gillespie, D., 2014. "The effect of impingement jet heat transfer on casing contraction in a turbine case cooling system". In ASME Turbo Expo 2014, Dusseldorf, Germany, Paper No. GT2014-26749.

[9] Dann, A., Thorpe, S., Lewis, L., and Ireland, P., 2014. "Innovative measurement techniques for a cooled turbine casing operating at engine representative thermal conditions". In ASME Turbo Expo 2014, Dusseldorf, Germany, Paper No. GT2014-26092.

[10] Van Paridon, A., Dann, A., Ireland, P., and Bacic, M., 2015. "Design and development of a full-scale generic transient heat transfer facility (THTF) for air system validation". In ASME Turbo Expo 2015, Montreal, Canada. GT2015-42391.

[11] Corren, D., Atkins, N., Turner, J., Eastwood, D., Davies, S., and Dixon, R., 2010. "An advanced multiconfiguration stator well cooling test facility". In ASME Turbo Expo 2010, Amer Soc Mechanical Engineers, pp. 1259-1270.

[12] Lattime, S., Steinetz, B., and Robbie, M., 2005. "Test rig for evaluating active turbine blade tip clearance control concepts". J Propul and Power, 21(3), pp. 552-563.

[13] Rolls-Royce Ltd, 2005. The Jet Engine, 5th ed. RollsRoyce, London.

[14] BSI, 1990. Steels for pressure purposes - Part 3: Specification for corrosion-and heat-resisting steels: plates, sheet and strip, BS 1501-3:1990. British Standards Institute.

[15] Florschuetz, L. W., Metzger, D. E., and Truman, C. R., 1981. Jet array impingement with crossflow - correlation of streamwise resolved flow and heat transfer distributions. Tech. rep., NASA Contractor Report 3373.

[16] Goldstein, R. J., and Seol, W. S., 1991. "Heat transfer to a row of impinging circular air jets including the effect of entrainment". Int. J. Heat Mass Transfer, 34(8), pp. 2133-2147.

[17] BSI, 2000. Tool Steels, BS EN ISO 4957:2000. British Standards Institute.

[18] Hay, N., and Lampard, D., 1998. "Discharge coefficient of turbine cooling holes: A review". J Turbomach, 120, pp. 314-319.

[19] McGreehan, W. F., and Schotsch, M. J., 1988. "Flow characteristics of long orifices with rotation and corner radiusing". J Turbomach, 110, April, pp. 213-217.

[20] Swamee, P. K., Ojha, C. S. P., and Kumar, S., 1998. "Discharge equation for rectangular slots". J Hydraul Eng, 124(9), pp. 973-974.

[21] Wu, D., Burton, R., and Schoenau, G., 2002. "An empirical discharge coefficient model for orifice flow". Int J Fluid Power, 3(3), pp. 13-18.

[22] ASM International, 1990. ASM Handbook, Volume 1, Properties and Selection: Irons, steels and high performance alloys, 10th ed. American Society of Metals.

[23] Buttsworth, D. R., and Jones, T. V., 1997. "Radial conduction effects in transient heat transfer experiments". Aeronaut J, 101(1005), May, pp. 209-212. 


\section{Appendix A: Derivations \\ Derivation of Explicit Solution to Heat Conduction in a Finite Wall}

In order to infer the inner wall heat transfer coefficient based on the temperature measurements recorded at the outer wall, which interfaces with a cooled cavity, the casing system was defined as a plane finite wall with heat conduction, illustrated in Fig. 19. The assumption of a plane wall is valid in this case due to the large diameter of the casing and a small Fourier number [23].

Using the heat equation, the following 1-D boundary conditions were defined:

$$
\begin{array}{ll}
\frac{\partial^{2} T}{\partial x^{2}}=\frac{\rho c}{k} \frac{\partial T}{\partial t} & \\
-k \frac{\partial T}{\partial x}=h_{1}\left(T_{f}-T\right), & x=0 \\
-k \frac{\partial T}{\partial x}=h_{2}\left(T-T_{a}\right), & x=l
\end{array}
$$

The above boundary conditions are not homogeneous and so it is not possible to use method of separation of variables. However, by introducing substitution:

$$
T(x, t)=z(x, t)+a x+b
$$

The above is transformed into:

$$
\begin{gathered}
\frac{\partial^{2} z}{\partial x^{2}}=\frac{\rho c}{k} \frac{\partial z}{\partial t} \\
-k \frac{\partial z}{\partial x}-k a=h_{1} T_{f}-h_{1} z-h_{1} b, \quad x=0 \\
k \frac{\partial z}{\partial x}-k a=h_{2} z+h_{2} a l+h_{2} b-h_{2} T_{a}, \quad x=l
\end{gathered}
$$

By solving $a, b$ to get homogenous boundary conditions:

$$
\begin{aligned}
& -k \frac{\partial z}{\partial x}=-h_{1} z, \quad x=0 \\
& -k \frac{\partial z}{\partial x}=h_{2} z, \quad x=l
\end{aligned}
$$

where $a, b$ are given by:

$$
\begin{aligned}
a & =\frac{h_{1} h_{2}\left(T_{a}-T_{f}\right)}{k\left(h_{1}+h_{2}\right)+h_{1} h_{2} l} \\
b & =\frac{k\left(h_{1} T_{f}+h_{2} T_{a}+h_{1} h_{2} \frac{l}{k} T_{f}\right)}{k\left(h_{1}+h_{2}\right)+h_{1} h_{2} l}
\end{aligned}
$$

Given these boundary conditions, the Laplacian $\nabla^{2}=$ $\frac{\partial^{2} x}{\partial x^{2}}$ is Hermitian and therefore there exists an orthonormal basis set of the eigenfunctions that spans the space bounded by the boundary conditions. We can therefore express the solution to our problem as a linear sum of the orthonormal basis functions (e.g. eigenfunctions) of the Laplacian, where the coefficients vary with time:

$$
z(x, t)=\sum_{m=1}^{m=\infty} \phi_{m}(t) \psi_{m}(x)
$$

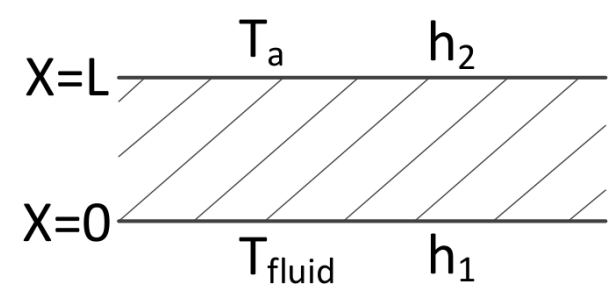

Fig. 19: Boundary conditions for transient heat conduction analysis

The particular solution to our heat equation is therefore $z_{m}(x, t)=\phi_{m}(t) \psi_{m}(x)$ and by substituting for this into (8), and discounting the unstable solution we define an eigenvalue problem:

$$
\frac{d^{2} \psi_{m}}{d x^{2}}=-\beta_{m}^{2} \psi_{m}
$$

that gives the eigenfunctions of the form:

$$
\psi_{m}(x)=A \sin \left(\beta_{m} x\right)+B \cos \left(\beta_{m} x\right)
$$

Substituting the above into the boundary conditions (9) gives the transcendental equation for the eigenvalues:

$$
\cot \left(\beta_{m} l\right)=\frac{k^{2} \beta_{m}^{2}-h_{1} h_{2}}{k \beta_{m}\left(h_{1}+h_{2}\right)}
$$

as well as $B / A=\frac{k \beta_{m}}{h_{1}}$. Since $A$ is not constrained, without loss of generality we can set $A=1$ and therefore write down the explicit solution for our thermal problem as:

$$
z(x, t)=\sum_{m=1}^{m=\infty} c_{m}\left(\sin \left(\beta_{m} x\right)+\frac{k \beta}{h_{1}} \cos \left(\beta_{m} x\right)\right) \exp \left(-\alpha \beta_{m}^{2} t\right)
$$

where $\alpha=\frac{\rho c}{k}$. 